\title{
Bubble Detection in the Malaysian Housing Market
}

\author{
Chee Yin Yip ${ }^{\mathrm{a}}$ \\ Universiti Tunku Abdul Rahman \\ Woei Chyuan Wong \\ Universiti Utara Malaysia \\ Hock Eam Lim ${ }^{c}$ \\ Universiti Utara Malaysia
}

\begin{abstract}
This study uses Phillips, Shi and Yu's (2015) bubble detection method to examine housing bubbles in Malaysia. We documented five positive bubbles and one negative bubble from 1988 to 2015, including the well-known 1997 Asian real estate bubble. The bubble that originated in April 2010 is the most prominent. It peaked in 2013. Since then, it has been exhibiting strong signs of gradual collapse but was still persisting up to the end of the study period in September 2015. Some of these bubbles preceded financial crises, a phenomenon which is consistent with the findings of contagion channels between real estate and financial markets in the literature.
\end{abstract}

Keywords: Bubble duration, consistency, dating algorithm, multiple bubbles, real time detector

JEL classification: R3, N2, G1, J10

\section{Introduction}

As the residential mortgage market turmoil in the US unfolded, the International Monetary Fund (IMF, 2008) in its Global Financial Stability Report in April 2008 estimated that that episode of turmoil could lead to an incredible potential global loss of US\$945 billion. The main cause of the US mortgage meltdown was the bursting of the housing bubble that took root in 2001 and reached its peak in 2006 (Bianco, 2008). ${ }^{1}$ The ensuing financial crisis that started in the US propagated globally and led to an unprecedented fall in global trade since World War II, resulting in the 2008-2009 global recession - the Great Recession. Many economies, both developed and developing,

a Faculty of Business and Finance, Universiti Tunku Abdul Rahman, 31900 Kampar, Perak, Malaysia. Email: cyyip@utar.edu.my

b School of Economics, Banking and Finance, Universiti Utara Malaysia, 06010 Sintok, Malaysia. Email: wwchyuan@uum.edu.my

c School of Economics, Banking and Finance, Universiti Utara Malaysia, 06010 Sintok, Kedah, Malaysia. Email: Iheam@uum.edu.my (Corresponding author)

We wish to thank the Higher Education Ministry for financially supporting this study through the FRGS research grant (FRGS/1/2016/SS08/UTAR/02/2). Special thanks are also due to Universiti Utara Malaysia for financial support at the early stage of this study through the PBIT research grant (Code S/O: 12617).

1 Bubbles in this paper are defined as boom-bust episodes which are characterised by sharp rise and rapid fall of prices. 
suffered severely. According to the World Trade Organization's (WTO) World Trade Report 2009, the economic growth of the developed nations for 2008 dropped to 0.8 percent compared to 2.5 percent in 2007 while that of the developing economies expanded by 5.6 percent only for 2008 compared to 7.5 percent a year earlier. In Malaysia, real gross domestic product (GDP) growth in 2008 was 4.6 percent down from 6.3 percent in 2007. As the full effect of the global crisis kicked in, the 2009 economic growth further deteriorated, contracting by 1.7 percent, the first real GDP contraction since third quarter 2001 (Bank Negara Malaysia, 2010). The magnitude and severity of the negative spillovers from the 2008-2009 global crisis are well documented and analysed in various literature particularly by world bodies such as the IMF and WTO (see, for example, IMF, 2009a; 2009b; WTO, 2009). This is a recent historical event that illustrates the adverse effects of bubbles, particularly in relation to the real estate market. Turmoil in the real estate market had in the past been the primary cause of serious recession and financial crises. Indeed, Reinhart and Rogoff (2009) claimed that financial crises throughout history have always started with some kind of asset price inflation in which house prices is a major component and that this pattern is remarkably consistent for emerging as well as advanced economies. This view is shared by financial historians such as Ahamed (2009) and Ferguson (2008) who have also advocated that financial crises are often preceded by an asset market bubble or rampant credit growth. Given the crippling effects of bubbles that could cascade to the socio-economic sectors, governments and policy makers alike are keen to identify bubble built-up, its potential intensity and transmission effects so as to take appropriate strategy to deflate it before it bursts.

The housing sector is an essential component of the economy. It has multiple roles. Housing is for shelter and also an investment instrument. Housing is the largest component of household wealth in many countries. Real estate constitutes over onethird of the value of the investable capital assets in the US (Geltner, Miller, Clayton, \& Eichholtz, 2007). In the Malaysian context, Malaysia experienced a severe bubble during the period 1993-1998. House prices ran up by about 13 percent year-on-year between 1993 and 1995, and then falling sharply by as much as 25 percent year-on-year over 1995-1998. For the period 2007-2008, Malaysia experienced another short duration bubble which was the result of a spillover effect from the US subprime crisis. The latest series of severe house price expansion started from the later part of 2009. The uptrend turned around in 2013 and since then has been charting a gradual down slope, still persisting at the end of this study period. This latest episode of house price fluctuations seems to have all the characteristics of a housing bubble. The construction sector of which residential housing is a major sub-sector, is one of the key components of the economy, contributing 11.6 percent to GDP in 2014 (Bank Negara Malaysia, 2015). Like many countries around the world, property prices in Malaysia have been escalating for the past decade. Nominal house prices rose by 21.2 percent between December 2000 and December 2014. To avoid a real estate bubble crash, Bank Negara Malaysia has taken various measures to moderate price increases and to curb speculation in the property market. The dramatic increase in house prices could also be driven by demand for housing, particularly so for a developing country such as Malaysia that has 
a relatively young population with rapid urbanisation rate. It is therefore important to establish whether this latest bout of excess volatility in the Malaysian housing market is due to the existence of a bubble or a response to strong demand for houses. Some convincing insightful findings on the housing price dynamics will assist policy makers in making the right choices for the sustainable growth of the housing sector.

The main objective of this paper is to examine the existence of bubbles in the Malaysian property market. Additionally, this paper also examines whether there exist an ongoing bubble which has not collapsed yet at the end of our study period as this can serve as an early warning to policy makers. In order to achieve the goal of this research, we propose to utilise specific econometric techniques which can detect exuberance in house prices. This method has to be not just ex post detection techniques but also anticipative dating algorithm that can assist regulators in their monitoring of market behaviour by conducting early warning diagnostic tests. Among the specific econometric techniques that can fulfil these objectives, Phillips et al.'s (2015) (hereafter PSY) method is most outstanding in identifying bubbles. As such we adopt the PSY's method to detect and time stamp explosive behaviour in the real estate prices controlling for fundamental value.

Our main findings in this study are as follows. Firstly, we detected various bubbles in the Malaysian housing market and some of these bubbles preceded well documented local and international financial crises. Secondly, by using price to income per capita (proxied by GDP per capita) ratio, we discovered that increase in income after 2010 cannot catch up with the rapid increase in house prices. Thirdly and most significant of all, the latest bubble detected commenced in 2010 and has since grown and peaked in 2013. It has started displaying signs of gradual weakening but persisted until the end of the research period of this study in 2015Q3. This bubble appears to be very prominent and persistent. Basing on market reports on the behaviour of prices in the Malaysian housing market, we believe that this bubble will persist into 2016 albeit on a descending path in view of the current falling crude oil prices, severe weakening of Ringgit to US Dollar, and global growth prospects impeded by uncertainties which will pose heavy challenges to the highly open economy of Malaysia.

The results of this study have convincingly shown that the Malaysian housing market has entered into a bubble state and as at the end of this study period in 2015Q3, it is on the downslope of the protracted severe price cycle. While the rising trend has reversed, prices are still very persistent and way above the pre-bubble level. This could mean that should some shocks that affect market sentiment arise, it could lead to panic selling and prices to fall precipitously. This can be considered as our main contribution in this paper. The bursting of the bubble could trigger much adverse consequences in view of the high level of household debts connected with home loan mortgage. In addition, our results have also revealed that the steep and rapid house price appreciation has caused a significant loss of affordability. While it is pertinent to check speculation, it is also vital to identify the contributing factors that support the increase in the fundamental housing prices. Hence, this study offers an approach to identify the existence of bubble in the market as well as to monitor the progression of an on-going bubble. Such information will have significant implications for countervailing policies. It identifies the form and the magnitude of the problem so 
that appropriate measures can be taken to evaluate the market movements as well as drawing up guidelines to the housing industry to maintain sustainability.

The rest of this paper is organised as follows. The second section provides the theoretical framework and review of literature on bubble detection methods. Section three explains empirical methodology and data used in this research. Section four reports the empirical results. Finally, a conclusion is provided in section five.

\section{Theoretical Framework and Literature Review}

\subsection{Rational Speculative Bubbles}

This section explains the selection of theoretical framework leading to the choice of methodology used in the analysis. Analysing the sharp and rapid rise of house prices, and basing on the notion of speculation by Shiller (2005) whereby investors' enthusiasm is spurred by news of price increase and success in financial gains by others, we hypothesise that the general trend of behaviour for Malaysian investors is that they follow some sort of herd instinct in a market environment that is flooded with news of investors gaining good returns from their investments in houses. The exuberant sentiment brings in more speculators and thus more frenzy buying, creating a sense that prices will keep going up with total disregard of the fundamental levels. This is consistent with rational expectation assumption, leading to the choice of rational speculative bubbles, based on which, tests on explosive investors' behaviour which reflects the herd instinct can be formulated. Thus, the theoretical framework for rational speculative bubbles is as follows.

In equilibrium, under no-arbitrage condition and the assumption of risk neutrality, the house price at time $t$ equals the expected discounted payoff received at time $t+1$ :

$$
P_{t}=\frac{1}{D_{t+1}} E_{t}\left(P_{t+1}+R_{t+1}\right)
$$

where $P_{t}$ is the real house price at time $t, R_{t}$ is the rent received from time $t-1$ to $t$ and $D_{t}$ is the gross discount rate. Following Campbell and Shiller (1987) and Cochrane's (2005) approach and using a log-linear approximation of equation (1), we obtain the log-linear approximation of the log price to rent ratio:

$$
P_{t} / R_{t}=f_{t}+b_{t}
$$

where

$$
\begin{aligned}
& f_{t}=\phi /(1-\rho)+\sum_{i=0}^{\infty} \rho^{i} E\left(\Delta r_{t+1+i}-d_{t+1+i}\right) \\
& b_{t}=\lim _{i \rightarrow \infty} \rho^{i} E_{t}\left(\rho_{t+i}-r_{t+i}\right)
\end{aligned}
$$

with $f_{\mathrm{t}}$ as the fundamental component, $b_{t}$ the rational bubble component, $p_{t}=\log P_{t}$, $r_{t}=\log R_{t}, d_{t}=\log D_{t}, \rho=1 /\left[1+e^{\overline{p / r}}\right]$ with $\overline{p / r}$ being the average log price to rent ratio. Equation (4) shows that when the actual price exceeds that implied by the 
fundamentals, we have the strictly positive bubble component. In that situation, the investor is expected to be compensated by the appreciation of the bubble component. Put it differently, investors are willing to pay a premium over the fundamental price only because they expect this premium to appreciate in the next period. This behaviour is completely consistent with the rational expectation assumption. Thus, this gives rise to the term 'rational bubble' and based on this asset pricing theory, a test for the presence of bubble can be formulated as a test for explosiveness in log price to rent ratio, $p_{t} / r_{t}$ or log price to income ratio or price to consumer price index ratio.

However, in Malaysia, there is the problem of data limitations especially rent and income index and moreover, price-rent/price-income ratios ignore the equilibrium values which are driven by fluctuations in economic fundamentals, for example, rent growth, income growth and the desired rate of returns. As a result, we select price to consumer price index (CPI) instead for the analysis in this study. Using CPI as the base has the following advantages. Since the imputed rent is included in the CPI computation together with a basket of other consumer products, CPI would better reflect the state of rent rates in relation to the general consumer market dynamics. Price to CPI ratio is known as real house price. A number of papers such as Grossman, Pavlidis and Paya (2015) have used price to CPI ratio besides using price to rent and price to income ratio to examine the exuberant behaviour of house prices.

\subsection{Literature Review}

Numerous studies have attempted to detect bubbles in the asset markets since the introduction of Blanchard and Watson's (1982) rational speculative bubbles. In theory, the fundamental value for a real estate is determined by the present value of its future expected cash flows in the form of rental income. However, property prices and rents at the individual property level are typically not available. ${ }^{2}$ Researchers have overcome this data limitation by using the aggregate ratio of house price and rents as an indicator of housing market conditions (Mikhed \& Zemcik, 2009; Shiller, 2007). High value of price-rent ratio is an indication of housing bubbles. Other aggregate indicators used include price-income ratio, interest costs, ratio of mortgage to house sales, housing supply and survey of investor sentiments (see Lind, 2009). These broad indicators provide a quick gauge on the existence of bubbles without relying on econometric equations.

Robust econometric techniques to detect a bubble could be performed if reliable time series data is available. A commonly adopted approach is to analyse the stationarity process of the house price and market fundamental factors (e.g. household income, GDP, construction indicators, etc.) using unit root and co-integration tests (Campbell \& Shiller, 1987; Diba \& Grossman, 1988). The existence of explosive bubbles in house prices is supported if: (i) house price is integrated of a higher order than their fundamentals; (ii) the residuals of regression of house prices on fundamental variables

2 Exceptions are Bracke (2015), and Smith and Smith (2006) that use microdata on prices and rents to compute and analyse the price-rent ratios of major cities in the UK and US respectively. 
is not stationary, I(0); (iii) there exist no long-run relationship between house prices and fundamental factors as evidenced by the absence of any cointegrating vector between these variables; and (iv) there is abnormal (or insignificant) interactions between house prices and market fundamentals using either a vector autoregressive (VAR) model or vector error correction model (VECM). ${ }^{3}$

Evans (1991) however contended that unit root and cointegration tests may not be able to detect the situation of periodically collapsing bubbles where the residual in the regressions of house prices and fundamentals make asymmetries adjustment towards the long-run equilibrium relationship. Specifically, house prices make sharp corrections once they have risen above a certain threshold relative to fundamentals. Cointegration tests may not be able to capture this non-linear behaviour in the formation of a bubble (Taylor and Peel, 1988). A number of methods have been recently proposed to counter the empirical issues of collapsing bubbles. Enders and Granger (1998) and Enders and Siklos (2001) for instance, developed momentum threshold autoregressive (MTAR) models that cater for the asymmetric adjustment of residuals in periodically collapsed bubbles scenarios. Taylor and Peel (1998) on the other hand advanced the residualsaugmented Dickey-Fuller (RADF) that corrected for skewness and excess kurtosis in the residuals of price-fundamentals regression due to the presence of periodically collapsing bubbles. The adjusted residuals, according to Taylor and Peel (1998), improved cointegration tests in detecting periodically collapsing bubbles.

A more recent bubble testing method which applies the sup ADF (SADF) and the generalised sup ADF (GSADF) is proposed by PSY (2015). This method allows the dating of the boom-bust episode and at the same time displays the power or magnitude of the boom-bust episode. Unlike MTAR and RADF tests that provide only indications of the existence of speculative bubbles, PSY's method is able to provide exact origination and termination dates of a bubble. Moreover, this method is able to handle the phenomenon of multiple bubbles. PSY (2015) showed that their method successfully identified well known bubbles such as Black Monday in October 1987 and the dot-com bubble which happened in the US stock market (S\&P pricedividend ratio) from January 1971 to December 2010. Yiu, Yu and Jin (2013) applied the PSY method on the Hong Kong housing market. They managed to identify 10 bubbles in the Hong Kong housing market from March 1993 to March 2011. The longest bubble lasted for six months (October 2007-April 2008) while the shortest bubbles lasted less than one month (June 2000, October 2004, January 2009 and January 2011). Similarly, this method is able to identify the well-known 1997 real estate bubbles in Hong Kong.

3 Unit root and cointegration tests were used by Nneji, Brooks and Ward (2013) and Hui and Yue (2006) to determine the existence of speculative bubbles in the US, Hong Kong, Beijing and Shanghai housing markets. Jirasakuldech, Campbell and Knight (2006) used these tests to detect the speculative bubbles in securitized real estate market in the US. Nneji et al. (2013) for instance found that house prices and rents in the US were cointegrated in the 1960-1999 period but not in the 2000-2011 period. This supports the existence of speculative bubbles post-1999. Moreover, VAR and VECM tests which explore whether rents granger cause the change in real estate prices support this hypothesis where changes in rents do not predict house price returns. 


\section{Empirical Methodology and Data}

\subsection{PSY Method}

The PSY method assumes that housing prices are subject to pricing errors and/or timevarying discount factors which induce the formation of financial exuberance through price bubbles. The PSY procedure can be implemented by repeatedly conducting the right-tailed ADF unit root tests on multiple recursive regressions using subsets of the base data incremented by one observation at each run. The initial analysis is based on a standard random walk process with a drift. In its simplest form, the regression is given by equation (5):

$$
\Delta p_{t}=\mu+(\rho-1) p_{t-1}+u_{t}
$$

where $p_{t}$ is the real price of the asset and $u_{t}$ is the error term. The null hypothesis is unit root behaviour and the alternative hypothesis is explosive behaviour given as:

$$
H_{0}: \rho=1 \text { and } H_{0}: \rho>1
$$

which indicates a positive tailed test (right tail).

The right-tailed ADF statistic is computed for every regression in a sequence of multiple recursive regressions with the number of observations and initial observation varying for each regression. The SADF statistic is then used to detect the presence of at least one bubble in the whole sample. In order to test for the existence of a rational bubble, the largest ADF denoted by SADF can be compared with right-tailed critical values obtained from the appropriate limit distribution. To date stamp the origin and collapse of a bubble, the recursive ADF statistics is then compared with an appropriate series of critical values.

Let $\delta_{0}$ be the fraction of the sample that corresponds to the minimum number of observations used in each regression. The ADF test will include observations $\delta_{0}=n \delta_{0}$ in the first regression with $n$ as the size of the total sample. Then, the sample is sequentially expanded to a size of $\delta_{0}=n \delta$ for $\delta_{0} \leq \delta \leq 1$. Next, let $\delta_{2}$ be the fraction corresponding to the last observation used in the regression. Then, let $\delta_{w}$ be the fractional window size of the regression with $\delta_{w} \geq \delta_{0}$ and $n$ total sample size. Thus the ADF test statistic obtained in a regression which starts in fraction $\delta_{2}-\delta_{w}$ and ending in fraction $\delta_{2}$ is given in equation (7) and the SADF test statistic is given in equation (8).

$$
\begin{aligned}
& D F_{\delta_{2}-\delta_{w}}^{\delta_{2}}=\left[n \delta_{w}\right](\hat{\rho}-1) \\
& \operatorname{SADF}\left(\delta_{0}\right)=\sup _{\delta_{t} \in\left[\delta_{0}, 1\right]} A D F_{\delta}
\end{aligned}
$$

where [.] represents the integer part. For date stamping the origin and $c v_{\delta}^{\alpha_{n}}$ collapse of a bubble, we denote the right-tailed critical value of the $A D F_{\tau}$ by $\alpha_{n}$ as the significance level. Then the origin date, $\hat{\delta}_{e}$ and the conclusion date $\hat{\delta}_{f}$ can be constructed as given in equation (9).

$$
\hat{\delta}_{e}=\inf _{\delta \geq \delta_{0}}\left[\delta: A D F_{\delta}>c v_{\delta}^{\alpha_{n}}\right], \hat{\delta}_{f}=\inf _{\delta \geq \delta_{e}}\left[\delta: A D F_{\delta}>c v_{\delta}^{\alpha_{n}}\right]
$$


Equation (9) essentially means that the origin date of the bubble is the date at which the first recursion for which the value of the ADF statistic of estimated $\rho$ is equal to or larger than the right side critical value, and the collapse date is the date on which the first subsequent recursion for which the ADF statistic drops back to or below the critical value.

To increase the power of the SADF test as described above, PSY proposes the GSADF test to cover a larger number of subsamples. Instead of only changing the ending point, $\delta_{2}$ the GSADF test allows for varying starting points, $\delta_{1}$ but within a feasible range from 0 to $\delta_{2}-\delta_{0}$. The GSADF test statistic is given by equation (10).

$$
\operatorname{GSADF}\left(\delta_{0}\right)=\sup _{\substack{\left.\delta_{\delta} \in \delta_{0}, 1\right] \\ \delta_{2} \in\left[0, \delta_{2}-\delta_{0}\right]}} A D F_{\delta_{1}}^{\delta_{2}}
$$

As for date stamping of origin and conclusion date, we apply the back expanding procedure which is characterised by the BSADF statistic and is given by equation (11).

$$
B S A D F_{\delta_{2}}\left(\delta_{0}\right)=\sup _{\delta_{1} \in\left[0, \delta_{2}-\delta_{0}\right]} A D F_{\delta_{1}}^{\delta_{2}}
$$

The origin and conclusion date for GSADF are given in equation (12).

$$
\hat{\delta}_{e}=\inf _{\delta_{2} \in\left[\delta_{0}, 1\right]}\left[\delta_{2}: B A D F_{\delta_{2}}\left(\delta_{0}\right)>c v_{\delta_{2}}^{\alpha_{\tau}}\right], \hat{\delta}_{f}=\inf _{\delta_{2} \in\left[\delta_{e}+\theta \log (n) / n, 1\right]}\left[\delta_{2}: B A D F_{\delta_{2}}\left(\delta_{0}\right)>c v_{\delta_{2}}^{\alpha_{\tau}}\right]
$$

As for the computation of critical values series, we use the following formula proposed by Yiu et al. (2012).

$$
C V_{\delta_{2}}=1.66+\log \left(\delta_{2} n\right) / 100
$$

where $n$ is the size of the sample.

\subsection{The Data}

The housing indices for overall market, medium level and high end segments are obtained from the Valuation and Property Services Department (VPSM) and Statistical Department of Malaysia. These are average house indices which have taken into consideration the building and neighbourhood effects on house prices. VPSM produces 117 house price indices covering national, state and district levels in Malaysia. These indices are further broken down into four property types, i.e. terraced house, highrise unit, detached house, and semi-detached. The average property price as at 2015Q3 based on this classification is as follows: terraced house (RM278,223), highrise (RM296,826), detached house (RM524,260), and semi-detached (RM469,823). In this paper, we define linked terrace houses as a medium segment of the housing market and detached and semi-detached houses as the high-end segment. And overall segment is the aggregate index covering all property types. The reason for this breakdown is that we would like to investigate the relative impact of the medium and high-end housing market on the exuberant investment behaviour of the investors. Overall segment is for the housing market as a whole which will provide a useful measure for the general health of the housing market in particular and economic 
growth in general. We examine the effect of the major component of the overall market mainly to facilitate the formulation of intervention policy in the housing market. This is similar in spirit with Yiu et al. (2013) that breaks the overall sample into mass and luxury segments.

The indices are in annual frequency from 1988Q1 to 1998Q4. For the period 1999 Q1 to $2015 Q 3$, the data is in quarterly frequency. For 198801 to 1999 Q 4 the index is based on year 1990, whereas for 2000Q1 to 2015Q3 it is based on year 2000. We convert all indexes based on 1990 to indexes based on 2000. This is possible because VPSM supplies indexes based on 1990 as well as 2000 for the year 1999. Since the PSY method operates better with more data, we convert the data frequency of housing indices from quarterly to monthly by using quadratic-match average method for frequency conversion. Thus, the data may not be as accurate as it should be. As for consumer price index and GDP per capita, we obtain the data from the Department of Statistics.

\section{Results}

\subsection{Graphical Analysis}

Figure 1 displays a line graph plot of the overall Malaysian real house price index for the period 1988 to 2015 . The real price index is defined as the nominal price index divided by the consumer price index (CPI). As can be seen in Figure 1, real house prices moved upward from 1988 to 1997 . The exuberance ended with a steep drop of 20 percent in house prices several months later following the Asian financial crisis at the end of 1997.

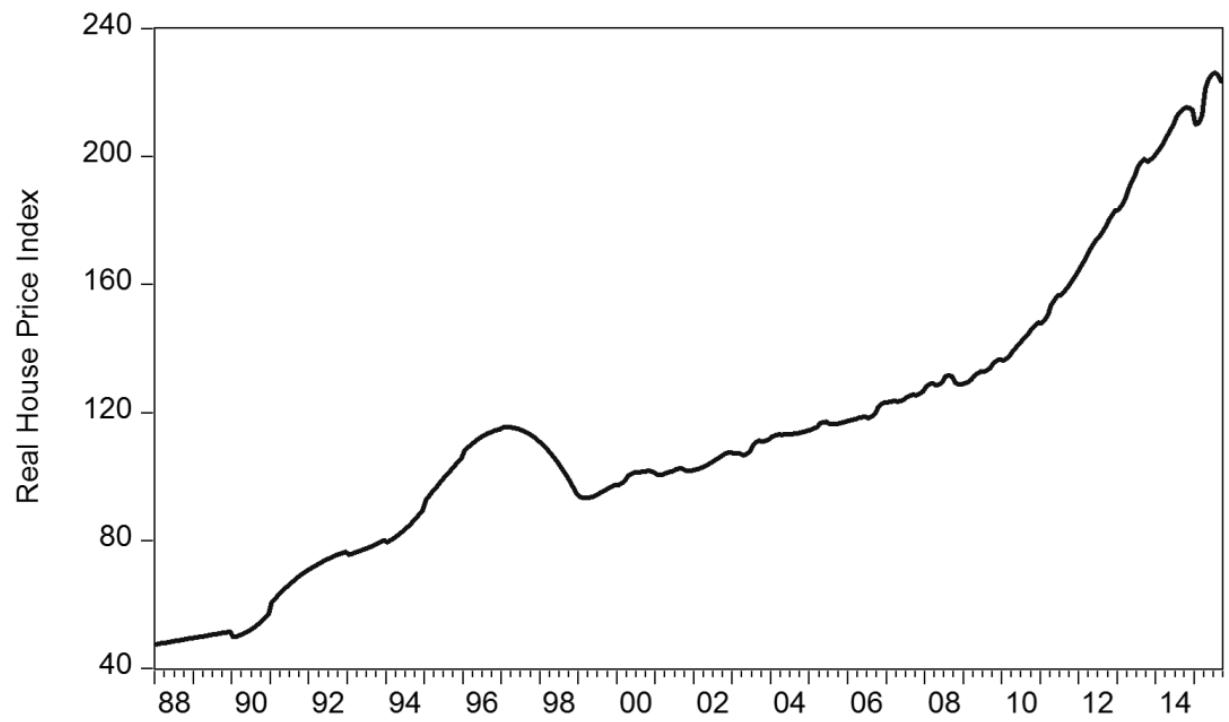

Figure 1. Real house price index from 1988M1-2015M9

Source: Real house price index obtained from Valuation and Property Services Department of Malaysia. 


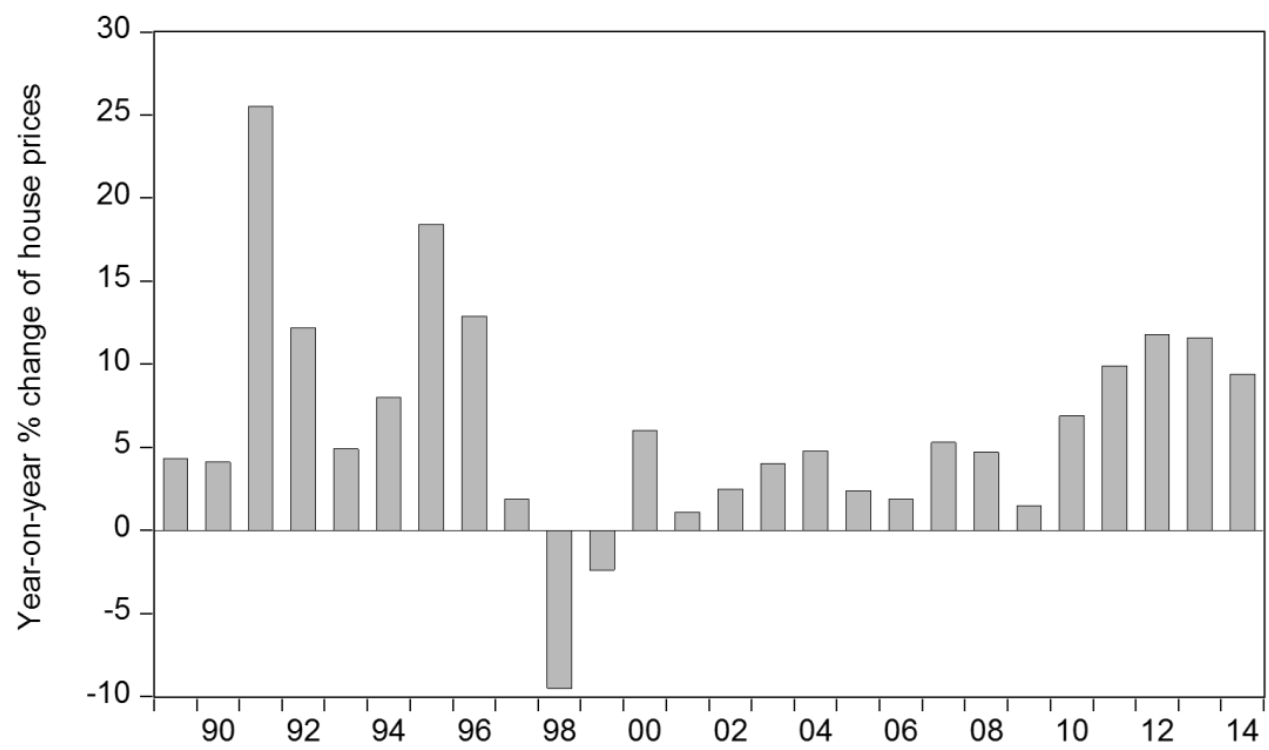

Figure 2. Year-on-year percentage change in real house price index from 1988-2015 Source: Real house price index obtained from Valuation and Property Services Department of Malaysia.

The market rebounded in year 1999 and had since then been experiencing an upward movement up to year 2015.

Figure 2 depicts a bar chart of yearly percentage increases in Malaysian house prices. The bar chart reveals that there are three distinct periods of exponential price growth, i.e. 1991-1992, 1995-1996 and 2012-2013 which are well above the average yearly increase during the study period. The average price growth during these periods was 18.9 percent (1991-1992), 15.7 percent (1995-1996), and 11.7 percent (2012-2013) against the average price growth of 6.3 percent from 1989 to 2014. These growth in prices are rather steep in comparison with the United States market over the ten-year period from 1995-2004, where national real house prices grew at an annual average of only 3.6 percent (see Himmelberg, Mayer, \& Sinai, 2005). One conclusion that can be made from this deviation through mean analysis is that it suggests the existence of an exuberant trading tendency on the part of the investors. Thus, based on this basic computation, we expect there are at least three discernible bubbles (1991-1992, 19951996, 2012-2013), that had occurred over the past 26 years.

Figure 3 shows real house price-to-GDP per capita ratio for overall, high-end and medium segments of the housing market. GDP per capita is assumed to proxy disposable income per capita. For the period before 2010, all three segments are charting on downward slopes, indicating that the rate of income increase is higher than that of house prices. This condition is in line with the buoyant Malaysian economy before the Asian financial crisis. However, for the period after 2010, a reversal trend emerged which saw a dramatic rise in price-GDP ratio since 2012 indicating the worsening of housing affordability problems during this period. 


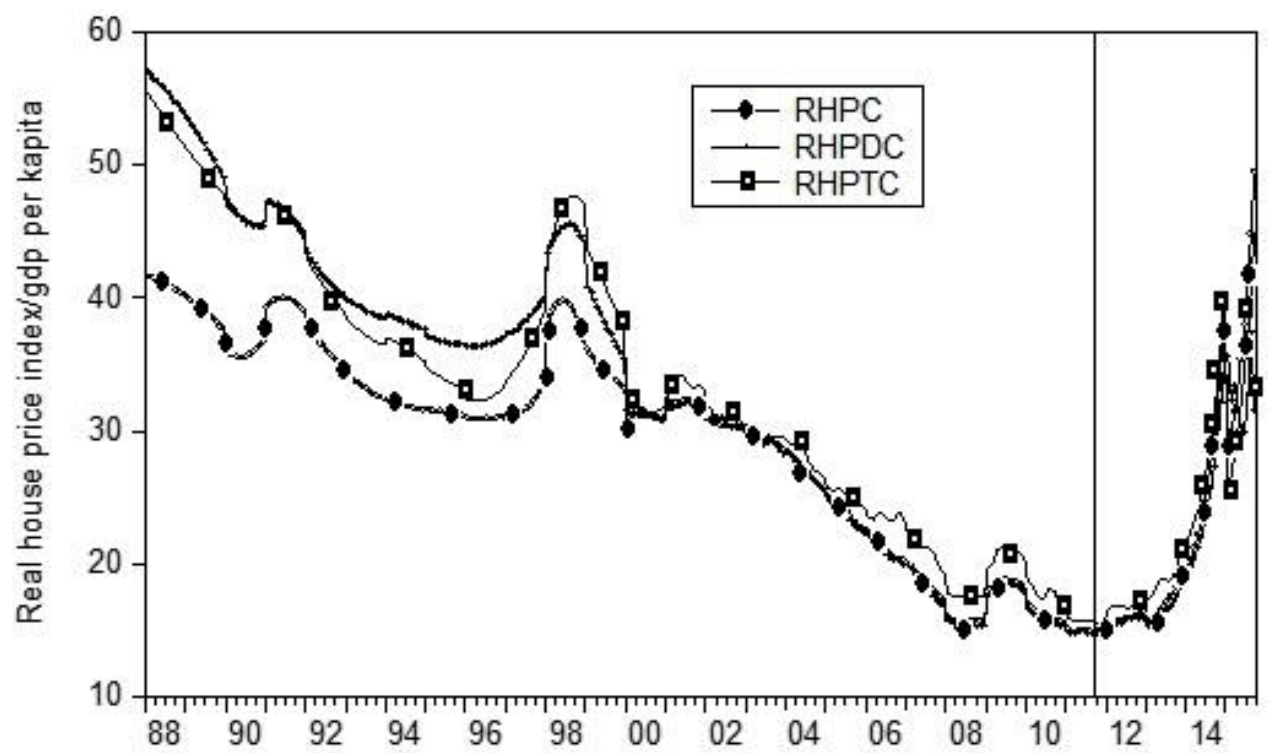

Figure 3. Real house price-to-GDP per capita for housing market from 1988-2015

Notes: $\quad$ RHPC $=$ Overall real house price index/GDP per capita. RHPDC $=$ High-end real house price index/GDP per capita. RHPTC $=$ Mid-level real house price index/GDP per capita.

Source: Real house price index/GDP per capita is obtained from the International Monetary Fund (IMF).

This result is in agreement with Bank Negara Malaysia's annual report (Bank Negara Malaysia, 2013) which stated that the rate of increase in income is getting slower than the rate of increase in house prices, thus making houses less affordable to a large section of the working population. It is possible that the escalation of house prices is fed by speculation. It is worth noting that both the high-end and medium level segments started to come down sharply in January 2000 to coincide with the overall, and then all three variables started to move almost parallel to one another. This sudden drop may suggest that prices for high and medium segment markets are dropping while prices remain steady for the overall market. This is because per capita income is the same for all three variables. In summary, graphical analyses in Figures 1-3 suggest the occurrence of housing bubbles in 1990, 1998, 2002, 2010 and 2013. We will confirm these bubble episodes more objectively in the next section using the PSY method.

\subsection{PSY Results}

This section describes the results obtained by applying the PSY strategy on three types of markets namely the overall, high-end and medium level segments of the Malaysian housing market. We apply the PSY method on the price to consumer price index (p/c) ratio for the overall, high end and medium level segments of the market from 1988 to 2015. Table 1 reports the supsup ADF statistic in all three cases with $\delta_{0}=16$, that is, 
Table 1. Supsup ADF (GSADF) and ADF statistics for the overall market and the two segments

\begin{tabular}{lccc}
\hline & Overall market & Middle level segment & High-end segment \\
\hline GSADF Stat & 23.56 & 18.24 & 10.46 \\
$10 \%$ CV & 2.47 & 2.47 & 2.31 \\
$5 \%$ CV & 2.77 & 2.77 & 2.72 \\
$1 \%$ CV & 3.47 & 3.47 & 3.51 \\
ADF to full sample 5\% level & -0.49 & -0.57 & -0.96 \\
\hline
\end{tabular}

Note: $\mathrm{CV}$ are critical values provided by Eviews7.

a minimum of 16 observations (about 5 percent of the total observations) are used in each regression. The minimum number of 16 observations used in each regression is to satisfy one of the criterions for running unit root test. Also reported are the 10 percent, 5 percent and 1 percent critical values of the supsup ADF statistic under the null hypothesis and the ADF statistic calculated from each of the full sample. In all three cases, the test statistics are much larger than the 1 percent critical value, suggesting overwhelming evidence of bubbles in the overall property market and its two individual segments. Interestingly, the test statistic for the high-end segment is the lowest. This difference occurs because our test statistic depends on the dynamic property of the gap, not on the level of the gap. However, if the standard unit root test is just applied to the full sample, bubbles in the overall, high-end and medium segment markets at the 5 percent level cannot be identified (the 95 percentile of the asymptotic distribution of the ADF test statistic is -2.87). This clearly indicates the weakness of the standard unit root test for detecting the presence of bubbles when bubbles are subjected to crash.

For time stamping bubbles in the overall market, high-end and medium level segments to locate specific bubble periods, we compare the backward sup ADF (BSADF) statistics with a critical sequence. Figures 4,5 and 6 each plots the statistics against for the overall, high end and medium level. The vertical lines and shaded areas are the identified bubbles. In total, the PSY method has detected six bubbles in the overall market, two in the high-end and four in the medium level segments.

\subsection{Time Stamping Bubbles in Overall Market}

As a guide for the verification of the timing of the bubbles identified in this study, we draw upon the research findings of Reinhart and Rogoff (2009) which suggest that financial crisis are always preceded by some kind of asset bubble. This phenomenon is valid for all categories of economies - from developed to emerging economies such as Malaysia (see also Claessens and Kose, 2013).

Table 2 illustrates some of the most recent financial crises which we would like to analyse whether identified bubbles in Malaysia are in line with this well recognised phenomenon. The identified periods with a positive or negative bubble are shown in Table 3. 
Table 2. Financial crises since 1988

\begin{tabular}{lll}
\hline Financial crisis & Period & Short summary \\
\hline Junk bond crash & $1989-1990$ & $\begin{array}{l}\text { Junk bond collapse, resulted in a significant recession in } \\
\text { the US, created financial ripples worldwide. }\end{array}$ \\
Tequila crisis & $1994-1995$ & $\begin{array}{l}\text { Sudden devaluation of Mexican Peso, triggered massive } \\
\text { interest crisis, interest hit as high as 20\%, hit interest rate } \\
\text { market in both developed and developing world. }\end{array}$ \\
Asian crisis & $1997-1998$ & $\begin{array}{l}\text { Thailand's baht collapsed because the country could not } \\
\text { pay up huge foreign debt, this crisis spread across the } \\
\text { Asian region. }\end{array}$ \\
Dotcom bubble & $1999-2000$ & $\begin{array}{l}\text { Bull rush into technology and internet-related stocks, } \\
\text { economy slowed down, interest rate goes up, causing } \\
\text { crash and reverberation throughout the world. }\end{array}$ \\
Global financial crisis & $2007-2008$ & $\begin{array}{l}\text { Billions lost due to collapse of large financial institutions, } \\
\text { global economy slowed down, main cause is US housing } \\
\text { market crashed. The effect spread across the world. }\end{array}$ \\
\hline
\end{tabular}

Source: Arbana, Safet and Drita (2012).

Table 3. Timing of bubbles and related financial crisis for the overall market

\begin{tabular}{|c|c|c|}
\hline No. & Timing of bubble & Preceded financial crisis \\
\hline 1 & 1990M08 - 1993M01 & the junk bonds crisis in 1991. \\
\hline 2 & 1994M07 - 1997M08 & the Asian financial crisis in 1997. \\
\hline 3 & 1998M01 - 1999M07 & the Dotcom bubble crisis in 2000 s. \\
\hline 4 & 2002M06 - 2003M04 & (economic growth recovered in 2003 with 5.4\% growth) \\
\hline 5 & $2006 \mathrm{M} 11-2008 \mathrm{M} 09$ & the global financial crisis \\
\hline 6 & 2010M04 - 2015M09 & $\begin{array}{l}\text { the } 2015 \text { oil and exchange rate crisis which may lead to global } \\
\text { recession. This is a positive bubble, occurred with a peak in } \\
\text { August 2013, at a value of } 10.2 \text {, which is twice the size of the } \\
\text { bubble in } 1997 \text { which has a value of } 5.8 \text {. }\end{array}$ \\
\hline
\end{tabular}

Note: M stands for month, for example M09 represents September.

Figure 4 presents several interesting empirical conclusions that can be drawn for the overall market. Firstly, we have an early bubble starting from 1990M08 to 1993M01 which preceded the 1994-1995 Tequila crisis started by the sudden devaluation of the Mexican Peso. Financial crises are contagious. Indeed according to the results of Doyle, Scott and Crimmins (1999), the Tequila crisis had raised investor alertness over the dynamics of economic fundamentals of other emerging economies in which they have put in their investments, making them more sensitive to possible economic setbacks in 


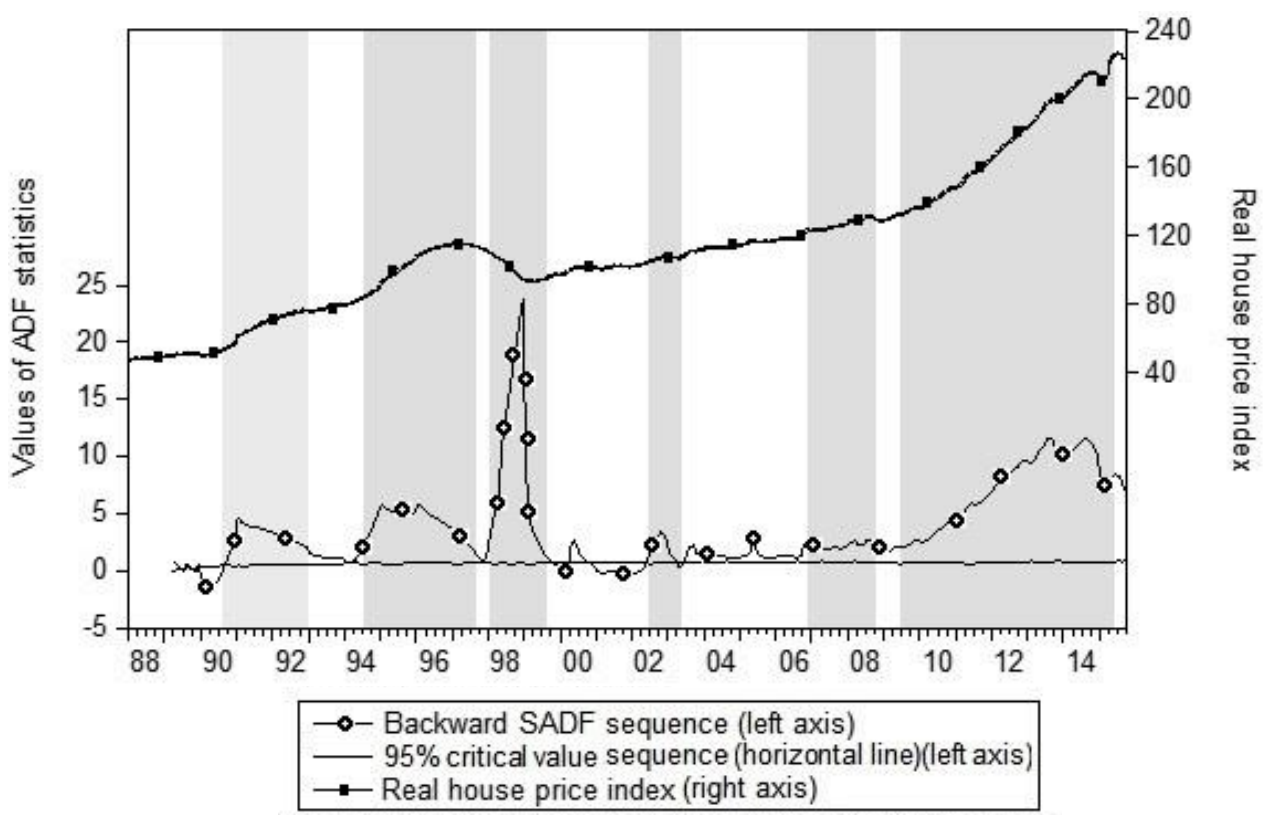

Figure 4. Backward sup ADF sequence (BSADF) for overall market

Note: The ADF statistical values above $95 \%$ critical value indicate bubble. The last bubble starting from 2010 has not collapsed yet.

those countries. Meanwhile, Krugman (2000) contended that earlier established studies have cast doubts on the impressive economic growth of the Asian tiger economies, revealing that productivity has not grown in tandem to sustain the real economy. He has argued that this is a major factor for the collapse of these tiger economies in the 1997 financial crisis. And in Malaysia the end result was the collapse of housing prices which by 1997 had already escalated to an all-time high following the earlier economic growth resulting in the bursting of the housing bubble. The bubble lasted for the period between November 1994M07 and July 1997M08 and most of the ADF statistics are much above the critical value. However, the bubble in early 1998M01 that ended in 1999M07 has not been discovered in Malaysian literature. It was a negative bubble (prices were sliding down) coinciding with the junk bond crisis in US, the effects of which propagated worldwide including Malaysia. Secondly, we discovered a somewhat shorted-lived bubble that occurred between 2002M06 and 2003M04. This bubble seemed to precede the 2007/2008 global financial crisis. However, we have observed that unlike other bubbles, there is a rather wide gap of three years between this bubble and the global financial crisis, which is considered as the global recession stemming from the US sub-prime mortgage meltdown. In view of this 3-year gap, we conclude that it did not precede the global financial crisis and its formation is mainly due to economic growth which recovered as much as 5.4 percent in 2003. Besides this bubble, we have discovered one more short lived bubble between 2006M11 and 2008M09. It is more plausible to say that this bubble preceded the global financial crisis. Finally, 
our method has identified a long duration bubble, starting from April $2010 \mathrm{M04}$ to September 2015M09 - the end of our dataset period. This last bubble is prominent in that it has the largest GSADF value of 10.2. Earlier researches on the Malaysian real estate market, including Bank Negara Malaysia's Report for 2012 (Bank Negara Malaysia, 2013), have concluded that no bubble has taken root yet. However this last bubble apparently defies the earlier findings. Based on the earlier established trend of asset bubble preceding financial crisis and the key role of external and domestic debts on financial crisis as asserted by Reinhart and Rogoff (2009), the findings of this study look more convincing given that at this point in time we are facing high financial stress level challenged by a deep weakening of the exchange rate of the local currency (currently hovering about 4.25RM/USD, an increase of about 20 percent for the second half of 2015) and the very high household debt, standing at 87.9 percent to GDP as at end 2014. Moreover, when analysing Figure 3, we have shown that in this period, Malaysia is facing a house affordability crisis in that income cannot catch up with house price increases. In addition to the debt and affordability crisis, we find that the 2013 prominent bubble can also be found in the high-end and medium level segments analysis by using the PSY method.

\subsection{Time Stamping Bubbles in High-end and Medium Level Segments}

The identified periods in the high-end segment showed two bubbles: 1994M011998M01 and 2010M11-2015M08 (Figure 5). Both bubble episodes are positive in nature. The bubble 2003M08-2004M08 found in the overall market is also detected in the medium level segment but not in the high-end segment, indicating that within

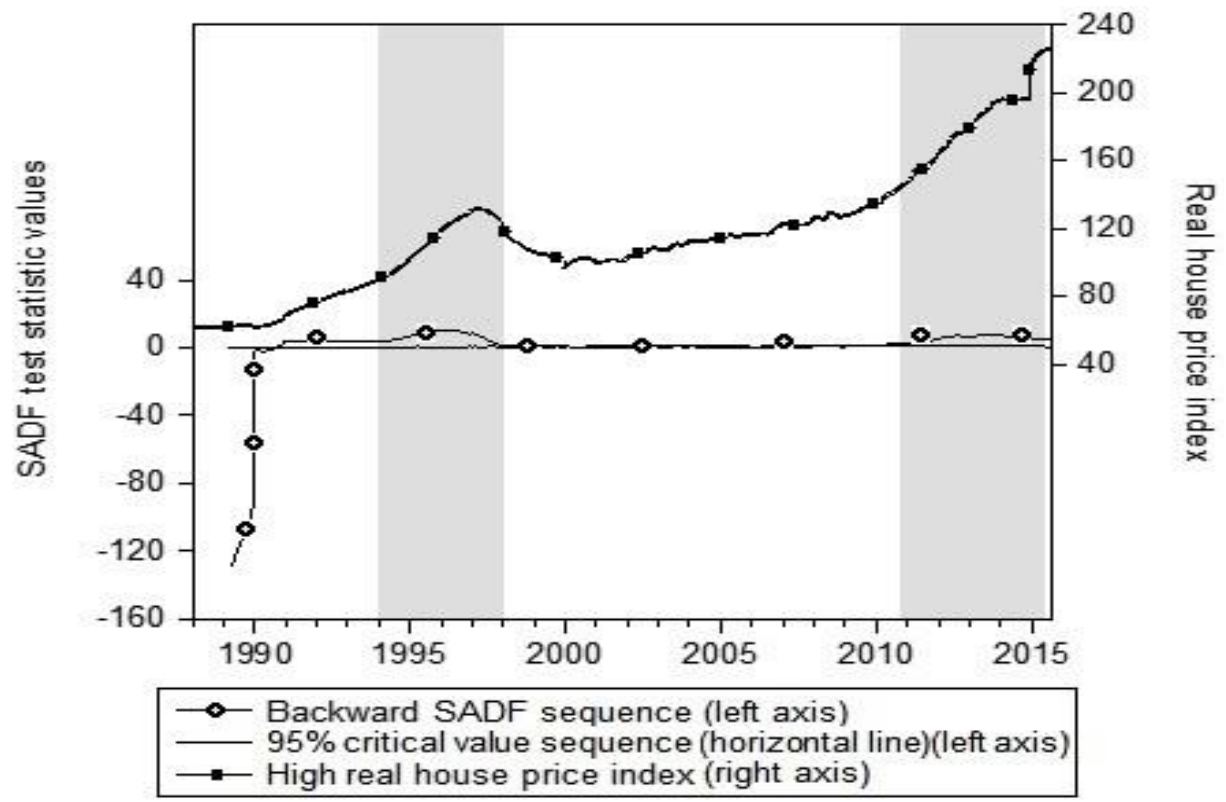

Figure 5. Backward sup ADF sequence (BSADF) for high-end segment 
this period, there is not much exuberant speculative activity in the high-end segment. This is evidenced by the values of the test statistics which is about half of the values of overall market and the medium level segment. As for the identified periods in the medium level segment in Figure 6, the bubbles included 1989M03-1998M03, 2003M102004M07, 2006M03-2007M02, and 2011M01-2015M06. The first bubble was rather long-lived. It started from 1989M03 till 1998M03. This period coincided with strong economic growth led by the booming electronic and electric industries. Family income increased tremendously, prompting young couples to buy terrace houses in areas near to their working places. Thus, this has caused an exuberant pattern of buying and selling of terrace houses both single and double storeys. The relatively short-lived bubbles of 2003M11-2004M05 cannot be found in the high-end segment and overall market which suggests a lack of strong evidence of speculative activities in the overall and high-end segment. This short lived bubble detected only in the medium level segment may be due to a series of prudent measures imposed by the Malaysian government to curb speculative activities and to safeguard financial stability of the banking sector. In particular, the earlier measures, such as reduction of loan-to-value ratio in mortgage loans in 2007 and the increase of stamp duty in July 2008, were particularly strenuous on high-end houses. On the other hand, for the bubble period identified, namely 2006M03-2007M02, macro-prudential measures did not fully mitigate the demand pressure from end-users who purchase mainly in the medium level segment. A plausible reason is the expected limited supply of medium cost residential properties in the near and medium terms. In fact, the 2009 economic stimulus package drawn up by the government included allocation for the increase in construction of low and

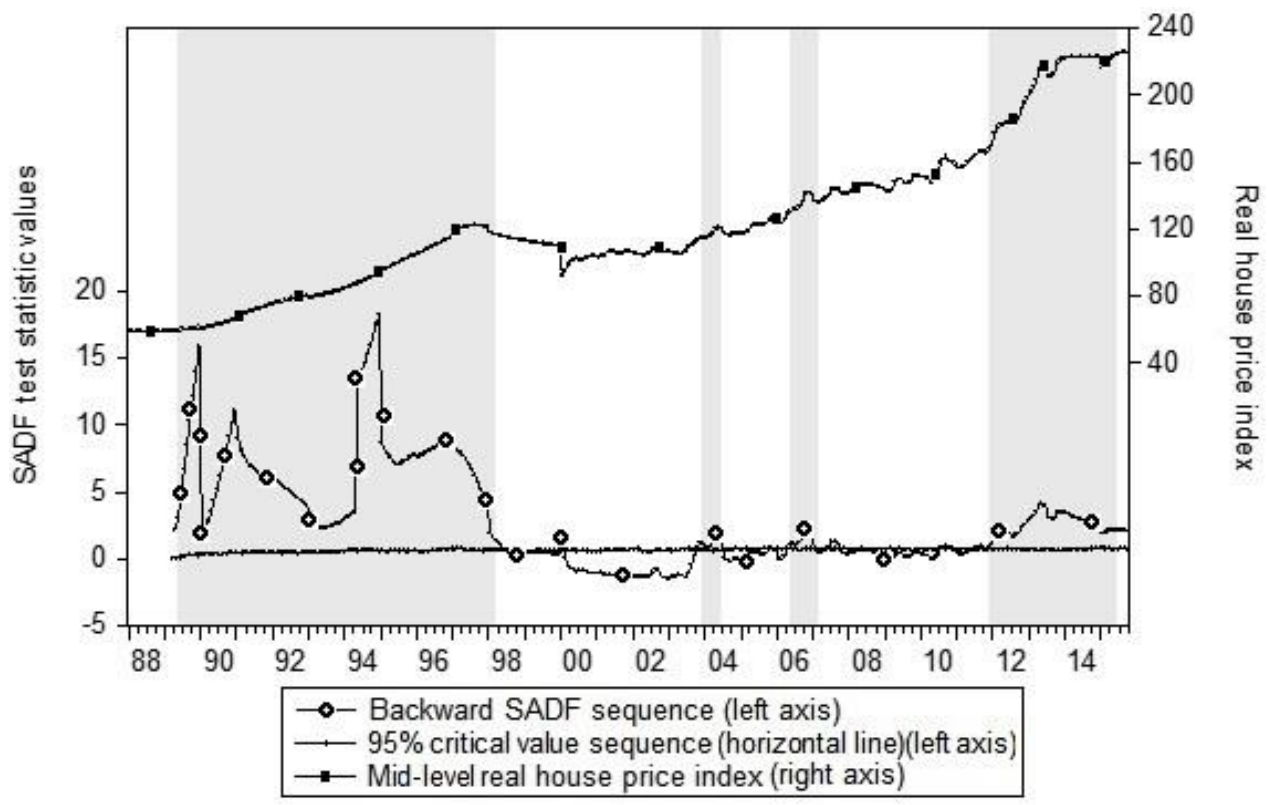

Figure 6. Backward sup ADF sequence (BSADF) for mid-level segment 
medium cost houses. This economic stimulus package was implemented too late to obtain any desirable effect. Moreover, house buyers/investors were cautious about the continuation of low mortgage rate conditions.

\section{Conclusion}

We have applied the PSY method to identify asset price bubbles in the Malaysian residential property market for the overall market, high-end and medium level segments. This method has identified the well-known real estate bubble in 1996 and five other financial crises related to housing bubbles in the overall market. In addition, it has time-stamped the most recent bubble that started in 2010 and peaked in 2013. Out of the six bubbles, five are positive and one is negative (1998M06) in the overall market. In terms of magnitude, the bubble which peaked around $2013 \mathrm{M} 9$ is the strongest, followed by the one which peaked in 1998M12. These two strong bubbles continued to be valid for both the high-end and medium level segments. In addition, this method has also found a bubble in late 2003 in the overall market and in the medium level segment but not in the high-end segment. This result suggests that the bubble in late 2003 in the real estate market in Malaysia was primarily caused by the medium level segment under the demand pressure from end-users of small and medium sized terrace houses. Additionally, the negative bubble is seen in the overall market but not in the two individual segments. With respect to the bubble around 2013, it is the most prominent and consistent for the overall market, high-end and medium level segments. This is the strongest bubble identified and it has preceded the global oil crisis (oil prices dropped by more than 50 percent since the end of 2014) which surfaced around the middle of 2015, and the weakening of the exchange rate (about RM4.25/USD). Both events are still exerting particularly strong negative impact on the Malaysian economy. However, apparently this 2013 bubble has a protracted duration. Until the end of the dataset period 2015M09, this bubble has been going on for almost five years and still persisting. This can serve as an early warning for policy makers to design a suitable policy and to implement it effectively to ensure a soft landing for the economy. This longer duration could be the effect of financial control imposed by the Malaysian government to cool down the volatile housing market. Additionally, it is also found that some of the six bubbles identified in the overall market preceded a global financial crisis. If the findings of this study are of consideration, Malaysian policy makers should take the latest bubble phenomenon seriously and try to identify the factors driving the volatile situation and rally appropriate policies and measures to cushion the economy against the eventual collapse of the latest bubble, which can induce a severe financial crisis.

Although the PSY method is able to trace the starting and concluding date for historical bubbles, its ability can only enable us to study the formation and collapsing trend of bubbles. We can draw experiences from this study so as not to repeat the same mistakes in future. Nevertheless, if PSY detected a bubble which is still in the booming or collapsing state at the point of time, then this serves as an early warning to policy makers who can then design macro or financial legislations, for example by restricting bank borrowings, raising interest rate and property gains tax, to cool the 
property market so as to lengthen the collapsing periods. On the part of researchers, they have to find out what are the fundamental macro and financial variables which exert a greater impact on housing prices at that point of time.

\section{References}

Ahamed, L. (2009). Lords of finance: The bankers who broke the world. New York, NY: Penguin Press.

Arbana, S., Safet M., \& Drita, K. (2012). Types of financial crisis. Asian Journal of Business and Management Sciences, 2(12), 31-39.

Bank Negara Malaysia. (2010). Key Economic and Financial Statistics. Annual report 2009. Putrajaya: Percetakan Nasional Malaysia.

Bank Negara Malaysia (2013). Annual report 2012. Putrajaya: Percetakan Nasional Malaysia.

Bank Negara Malaysia (2015). Economic developments in 2014. Annual report 2014. Putrajaya: Percetakan Nasional Malaysia.

Bianco, K.M. (2008). The subprime lending crisis: Causes and effects of the mortgage meltdown. $\mathrm{CCH}$ Federal Banking Law Reporter, $\mathrm{CCH}$ Mortgage Compliance Guide and Bank Digest. New York, NY: CCH, Wolters Kluwer Law \& Business.

Blanchard, O.J., \& Watson, M.W. (1982). Bubbles, rational expectations, and financial markets. In P. Wachtel (Ed.), Crisis in the economic and financial structure (pp. 295-315). Lanham, MD: Lexington Books.

Bracke, P. (2015). House prices and rents: Micro evidence from a matched dataset in Central London. Real Estate Economics, 43(2), 403-431. doi: 10.1111/1540-6229.12062

Campbell, J., \& Shiller, R. (1987). Co-integration and tests of present value models. Journal of Political Economy, 95(5), 1062-1088. doi: 10.1086/261502

Claessens, S., \& Kose, M.A. (2013). Financial crises: Explanations, types and implications (IMF Working Paper WP/13/28). Washington, DC: International Monetary Fund.

Cochrane, J. H. (2005). Asset pricing. Princeton, NJ: Princeton University Press.

Diba, B.T., \& Grossman, H.I. (1988). Explosive rational bubbles in stock prices? The American Economic Review, 78(3), 520-530.

Doyle, R., Scott, D., \& Crimmins, C. (1999). Was the "Tequila Effect" Rational? Working Paper, Trinity College Dublin. Retrieved from https//www.tcd.ie/Economics/assets/pdf/SER/1999/ Doyle_Scott.pdf

Enders, W., \& Granger, C.W.J. (1998). Unit root tests and asymmetric adjustment with an example using the term structure of interest rates. Journal of Business and Economic Statistics, 16(3), 304-311.doi: 10.2307/1392506

Enders, W., \& Siklos, P. (2001). Cointegration and threshold adjustment. Journal of Business and Economic Statistics, 19(2), 166-176. doi: 10.1198/073500101316970395

Evans, G. (1991). Pitfalls in testing for explosive bubbles in asset prices. The American Economic Review, 81(4), 922-930. doi: 10.1.1.534.1909

Ferguson, N. (2008). The ascent of money. New York, NY: Penguin Press.

Geltner, D., Miller, N.G., Clayton, J., \& Eichholtz, P. (2007). Commercial real estate analysis and investment (2nd Ed.). Mason, $\mathrm{OH}$ : Thomson.

Grossman, H.L., Pavlidis, E., \& Paya, I. (2015). Episodes of exuberance in housing markets: In search of the smoking gun (Globalization and Monetary Policy Institute Working Paper No. 165). Dallas, TX: Federal Reserve Bank of Dallas.

Himmelberg C., Mayer, C., \& Sinai, T. (2005). Assessing high house prices: Bubbles, fundamentals and misperceptions. Journal of Economic Perspectives, 19(4), 67-92. doi: 10.1257/ 089533005775196769 
Hui, E.C.M., \& Yue, S. (2006). Housing price bubbles in Hong Kong, Beijing and Shanghai: A comparative study. The Journal of Real Estate Finance and Economics, 33(4), 299-327. doi: 10.1007/s11146-006-0335-2

International Monetary Fund (IMF). (2008). Global financial stability report, April 2008: Containing systemic risks and restoring financial soundness. Washington, DC: Author.

International Monetary Fund (IMF). (2009a). World economics and financial surveys - World economic outlook, April 2009: Crisis and Recovery. Washington, DC: Author.

International Monetary Fund (IMF). (2009b). World economics and financial surveys - Regional economic outlook - Asia and Pacific - Global crisis: The Asian context, May 2009. Washington, DC: Author.

Jirasakuldech, B., Campbell, R.D., \& Knight, J.R. (2006). Are there rational speculative bubbles in REITs? The Journal of Real Estate Finance and Economics, 32(2), 105-127. doi: 10.1007/ s11146-006-6010-9

Krugman, P. (2000). A short course in miracles: Asia before the crisis. In P. Krugman, The return of depression economics and the crisis of 2008. Middlesex, England: Penguin Books Limited.

Lind. H. (2009). Price bubbles on the housing market: Concept, theory and indicators (Working Paper No. 58, Section for Building and Real Estate Economics, Department of Real Estate and Construction Management, School of Architecture and the Built Environment). Stockholm: Royal Institute of Technology.

Mikhed, V., \& Zemcik, P. (2009). Testing for bubbles in housing markets: A panel data approach. The Journal of Real Estate Finance and Economics, 38(4), 366-386. doi: 10.1007/s11146-0079090-2

Nneji, O., Brooks, C., \& Ward, C. (2013). Intrinsic and rational speculative bubbles in the US housing market: 1960-2011. Journal of Real Estate Research, 35(2), 121-152.

Phillips, P.C., Shi, S.P., \& Yu, J. (2015). Testing for multiple bubbles: Historical episodes of exuberance and collapse in the S\&P 500. International Economic Review, 56(4), 1043-1078.

Reinhart, C., \& Rogoff, K. (2009). This time is different: Eight centuries of financial folly. Princeton, NJ: Princeton University Press.

Shiller, R.J. (2005). Irrational exuberance (2nd Ed). New York: Crown.

Shiller, R.J. (2007). Low interest rates and high asset prices: An interpretation in terms of changing popular economic models. Brookings Papers on Economic Activity, 38(2), 111-134. doi: 10.3386/w13558

Smith, M.H., \& Smith, G. (2006). Bubble, bubble, where's the housing bubble? Brookings Papers on Economic Activity, 37(1), 1-67. doi: 10.1353/eca.2006.0019

Taylor, M.P., \& Peel, D.A. (1988). Nonlinear mean-reversion in real exchange rates. Mimeo, Department of Economics. Oxford: University of Oxford.

Taylor, M.P., \& Peel, D.A. (1998). Periodically collapsing stock price bubbles: A robust test. Economics Letters, 61(2), 221-228. doi: 10.1016/S0165-1765(98)00171-2

World Trade Organization (WTO). (2009). World trade report 2009: Trade policy commitments and contingency measures. Geneva, Switzerland: Author.

Yiu, M.S., Yu, J., \& Jin, L. (2013). Detecting bubbles in Hong Kong residential property market. Journal of Asian Economics, 28(October), 115-124. doi: 10.1016/j.asieco.2013.04.005 
